\title{
Manfred Mugrauer, Partei in Bewegung. 100 Jahre KPÖ in Bildern
}

Jean-Numa Ducange

\section{(2) OpenEdition}

Édition électronique

URL : https://journals.openedition.org/austriaca/1603

DOI : 10.4000 /austriaca. 1603

ISSN : 2729-0603

\section{Éditeur}

Presses universitaires de Rouen et du Havre

\section{Édition imprimée}

Date de publication : 1 juin 2020

Pagination : $273-275$

ISBN : 979-10-240-1492-0

ISSN : 0396-4590

\section{Référence électronique}

Jean-Numa Ducange, "Manfred Mugrauer, Partei in Bewegung. 100 Jahre KPÖ in Bildern », Austriaca [En ligne], 90 | 2020, mis en ligne le 01 juin 2020, consulté le 08 octobre 2022. URL : http://

journals.openedition.org/austriaca/1603; DOI : https://doi.org/10.4000/austriaca.1603

Ce document a été généré automatiquement le 8 octobre 2022.

Tous droits réservés 


\title{
Manfred Mugrauer, Partei in Bewegung. 100 Jahre KPÖ in Bildern
}

\author{
Jean-Numa Ducange
}

\section{RÉFÉRENCE}

Manfred Mugrauer (dir.), Partei in Bewegung. 100 Jahre KPÖ in Bildern, Vienne, Globus Verlag, 2018, 448 p., ISBN : 978-3-9504648-2-6.

1 Pourquoi consacrer un ouvrage aussi volumineux à une organisation politique demeurée très minoritaire tout au long de son histoire ? L'histoire du Parti communiste autrichien (KPÖ) peut sembler être en effet un aspect tout à fait marginal de l'histoire politique du pays si l'on s'en tient à ses résultats électoraux à l'échelle d'un siècle (5\% au plus haut au lendemain de la Seconde Guerre mondiale), ou même à ses effectifs militants qui demeurèrent toujours nettement inférieurs aux grandes forces politiques.

Néanmoins, à plusieurs reprises, ses membres jouèrent un rôle non négligeable : après l'effondrement de la social-démocratie en février 1934, certains sociaux-démocrates le rejoignirent, puis le parti participa pleinement la résistance au nazisme. En 1945, le KPÖ fut, avec l'ÖVP et le SPÖ, le troisième parti à signer la déclaration d'indépendance $\mathrm{du}$ pays, et tant que les troupes soviétiques stationnèrent, il joua un rôle de relais important. Et même après 1955, alors que son influence sur la vie politique nationale demeurait très limitée, certaines personnalités y restèrent plusieurs décennies, tout en étant des figures connues et reconnues hors du parti. On pense, par exemple, à Ernst Fischer (exclu en 1969 pour avoir soutenu le Printemps de Prague), au rôle politique et intellectuel important, ou, dans un tout autre registre, à l'écrivaine Elfriede Jelinek, qui en fut membre jusqu'en 1991.

3 Le présent ouvrage, préparé par Manfred Mugrauer (historien spécialiste de la période 1945-1955 et l'un des principaux animateurs de l'Alfred Klahr Gesellschaft, qui gère notamment les archives du KPÖ à Vienne), apporte de ce point de vue des éléments intéressants sur cette histoire. S'il s'agit explicitement d'un ouvrage 
commémoratif cherchant à valoriser l'apport du KPÖ à l'histoire du pays, la masse documentaire et archivistique mobilisée invite à ne pas sous-évaluer a priori l'ensemble, qui ne minimise d'ailleurs pas les crises internes et les limites de l'organisation (il serait au demeurant difficile d'écrire une histoire simplement héroïque d'un parti resté aussi minoritaire !).

4 L'impressionnante collection d'images, affiches de propagande et photographies de mobilisations sociales et politiques (dont certaines très rares, voire inédites) reproduite ici, avec des indications précises sur la provenance de chaque document, mérite à elle seule le détour: Partei in Bewegung pourra être ainsi consulté par toute personne susceptible de s'intéresser à l'histoire politique de l'Autriche et de l'Europe centrale (les croisements avec la RDA et la Tchécoslovaquie notamment étant nombreux). L'ensemble est particulièrement riche pour la période 1945-1955, tout particulièrement sur la forte présence de la culture soviétique à Vienne avant le traité de neutralité ; les premiers chapitres nous proposent également des documents rares à propos des premiers pas de la "révolution" autrichienne de 1918-1919. On relèvera aussi l'iconographie couvrant les années 1960-1980 qui nous propose un panorama assez complet des luttes sociales et pacifiques qui marquèrent les courants de la gauche autrichienne, au-delà du seul KPÖ. Soulignons que le volume est édité de telle façon que, si le KPÖ demeure toujours au centre, l'on s'intéresse à tous les mouvements auxquels les communistes prirent part, y compris lorsqu'ils ne pesaient que très peu, offrant ainsi un panorama assez large.

Personnalités de premier plan, cadres moins connus et militants anonymes jalonnent l'ouvrage. On remarquera la présence du fondateur d'Austriaca, Félix Kreissler, lorsque celui-ci travaillait en zone d'occupation soviétique... Du point de vue historiographique, ce n'est certes pas ici que l'on trouvera les développements les plus critiques sur la stalinisation du parti et ses liens avec les autorités soviétiques (encore que cette question soit traitée sans ignorer les aspects les plus sombres), et les résumés historiques demeurent trop brefs pour pouvoir rendre compte des multiples réalités du communisme autrichien. Mais telle n'était pas l'ambition du présent ouvrage ; comme ensemble documentaire, il peut être considéré comme une contribution importante à l'histoire d'un courant de critique radicale de l'ordre politique en Autriche depuis un siècle. 